\title{
What Constraints the Expansion of Urban Agriculture in Benin?
}

\author{
Mawuna Donald Houessou ${ }^{1,2,3, * \mathbb{C}}$, Mirte van de Louw ${ }^{1}$ and Ben G. J. S. Sonneveld ${ }^{1,4}$ \\ 1 Athena Institute/Vrije Universiteit Amsterdam, De Boelelaan 1085, 1081 HV Amsterdam, The Netherlands; \\ mirtevandelouw@gmail.com (M.v.d.L.); b.g.j.s.sonneveld@vu.nl (B.G.J.S.S.) \\ 2 Laboratoire d'Etude sur la Pauvreté et la Performance de l'Agriculture (LEPPA), Faculty of Agricultural \\ Sciences, University of Abomey-Calavi, 03 BP 2819 R.P. Cotonou, Benin \\ 3 Centre d'Actions pour l'Environnement et le Développement Durable, BP 660 Abomey-Calavi, Benin \\ 4 Amsterdam Centre for World Food Studies, De Boelelaan 1085, 1081 HV Amsterdam, The Netherlands \\ * Correspondence: m.d.houessou@vu.nl; Tel.: +229-96091680
}

Received: 26 May 2020; Accepted: 15 July 2020; Published: 17 July 2020

\begin{abstract}
Propelled by rapid urbanization, city administrations in low- and middle-income countries face a raft of challenges to secure food and nutrition for its poor urban dwellers. Urban agriculture (UA) seems a viable intervention to address urban food insecurity, however, experience has shown that urban gardens do not expand at the expected rate. Tackling this issue requires a deeper understanding of the main constraints that block UA expansion. Benin is not an exception; the country witnesses a breathtaking growth of its main cities that is in synchronization with a mounting food insecurity. Our research aims, therefore, to identify the main constraints for the expansion of UA in Benin, and adopt a three-pronged approach combined with a systematic literature review, a survey held among experienced urban gardeners, and in-depth interviews with stakeholders. Altogether, the synthesis shows a predominance of five main constraints: lack of land and tenure insecurity, insufficient government support, restricted market access, limited access to productive factors, and inequality issues. Specifically, while the review showed that most barriers are linked and could be tackled together, the survey indicated a political unwillingness which in our in-depth interviews is explained by the unperceived benefits of investing in UA and the lack of enforcement of urban development plans. We suggest that Beninese authorities and academics move in synchronization where the former coordinates the planning of urban gardens and the latter provides evidence to trigger public and private investments in UA. The findings could be the basis for further research on UA in West Africa and the wider continent.
\end{abstract}

Keywords: urban farming; urban agriculture; cities; drivers; barriers; urban planning; urbanization; land tenure; low- and middle-income countries; Benin; Africa

\section{Introduction}

Rapid urbanization in low- and middle-income countries is challenging traditional approaches to food and nutrition security (FNS), as well as the established thinking on how cities are fed [1]. Indeed, the usual pattern is that food will be produced in rural areas and transported into urban areas to cover the food needs of urban population. However, the expedited urban population growth induces an increase in the demand for food, putting serious competing claims on the natural resource base (land, water) that serves as factors for food production. In addition, a growing poor population in low- and middle-income countries is living in urban areas with few capacities to produce its own food. For instance, Ravallion, et al. [2] estimate that twenty-five percent of the developing world's poor live in urban areas with minimal access to food; they also conclude that the number of poor urban 
dwellers is rapidly expanding. Furthermore, perishable fresh food products such as vegetables are either not available or inaccessible for the urban poor who cannot afford to pay the high prevailing prices. Hence, cities become FNS hotspots that face serious challenges for the wellbeing of their inhabitants, especially for lower-income groups.

Urban agriculture (UA) figures prominently among the most viable interventions to address food insecurity in urban areas. UA, defined as growing plants and raising animals within and around cities [3], is practiced by 800 million people worldwide and helps low-income urban residents save money on food purchases [4]. Roughly $15-20 \%$ of the world's food is grown in urban areas, a figure that is likely to increase as cities continue to grow [5]. UA encompasses various forms depending on the criteria used for the classification (types of actors, location, products, technology, types of economic activities, and the degree of market orientation) [6]; using location criterion, home gardening and allotment gardening are two forms of UA. UA contributes to FNS and economic opportunities, especially when low-income communities which participate obtain direct access to locally produced fresh foods that widens the food diversity, while offering employment opportunities and generating some income by selling surplus produce [4,7]. UA potentially constitutes an important strategy for poverty alleviation and the social integration of disadvantaged groups in the urban socio-economic system. For instance, several UA projects that involve disadvantaged groups, such as female-headed households, recent immigrants, and unemployed youth, exist with the aim to integrate them more strongly into the urban network and to provide them with a decent livelihood (see e.g., in Havana, Cuba: [8], in Lagos, Nigeria: [9], in Cotonou and Porto-Novo, Benin: [10]. The projects not only resulted in food- and income-generating activities, but also in a higher self-esteem, enhanced self-management capacity and more interactions with other actors in the urban society. Furthermore, UA is part of the urban ecological system and can play an important role in the urban environmental management system by turning urban wastes into a productive resource such as compost or animal feed [11]. Finally, UA also contributes to a scenic, green, and more pleasant urban environment [12].

Despite its acknowledged important contributions in the social, economic, and ecological urban development, UA is not expanding in low- and middle-income countries against the rate that would be expected by its anticipated benefits. Poulsen, et al. [13], Warren, et al. [14], and Korth, et al. [15] investigated the association between UA and FNS through a systematic review of the literature (up to 2013) and concluded that there was a lack of robust evidence to substantiate that UA positively contributes to FNS. The lack of concrete evidence on the positive effect of UA on food and financial security might therefore explain the large absence of policies regarding its development. However, the presence of UA in all its forms, widely spread, and appreciated in other parts of the world, contradicts to a certain extent the premise that the absence of information is the main barrier for expansion. Hence, it is important to assess what the key blockades of the expansion of UA are.

The Republic of Benin is no exception. The poor West African country witnesses a stunning growth of its main cities that goes hand in hand with an increasing food insecurity in the Beninese metropoles. From 2002 to 2013, the country's population density increased from 59 to 87 inhabitants per square kilometer [16]. This increase was largely due to the fast-growing urban areas across the country. For instance, the city of Abomey-Calavi, in the south, doubled its population in the same decade, increasing from 307,000 to 656,000 inhabitants. In 2018 , more than $47 \%$ of the country's population was living in urban areas [17], facing cities with FNS challenges. For instance, the proportion of food-insecure people in Benin's urban areas approximately remained the same from $2013(8 \%)$ to $2017(7 \%)$, but the absolute number of food-insecure people significantly increased in that period, from around 332,000 to 449,000 inhabitants. Benin avails of a few examples of UA that positively impacted on the FNS situation of the gardeners and their families [10]. However, the concept of UA was not widely adopted in the urban areas of Benin.

Artmann and Sartison [18] and Wesener, et al. [19] conducted a systematic literature review on the important drivers and constraints of UA implementation in the Global North and on factors that support or obstruct the development of urban community gardens in the United States, Australia, 
Canada, the United Kingdom, South Africa, Germany, and New Zealand. However, we assume that these countries present different realities as compared to a low- or middle-income country's context which, to the best our knowledge, has been under researched, concerning the factors that impede UA development. In addition, Artmann and Sartison [18] argued that, independently of the number of times drivers and constraints that have been mentioned in the literature, specific case studies that prioritize stakeholders' perspectives might prove important to learn from each context. Hence, and to advance the international debate on the development of UA, our research aims to identify the main constraints for the expansion of UA in Benin, focusing on allotment gardens. Our focus is on allotment gardens because it is the most practiced form of UA in Benin and has the multiple benefits of collective action [10]. We therefore adopted a three-pronged approach. First, we held an international review of scientific literature related to the UA-FNS nexus in low- and middle-income countries, including peer-reviewed articles from 2013 to 2018 to ensure novelty. Second, we consulted the findings on the constraints and barriers for UA development derived from a survey held among 261 experienced gardeners in Benin. Third, we conducted a series of in-depth interviews with stakeholders focusing on political constraints that are impeding the broad implementation of UA.

The paper is structured in five sections. Section 2 presents the methodology used in this study. Section 3 describes the included studies in the review, the drivers, and the barriers to UA as well as the results of the survey and interviews. Section 4 discusses the results and brings out the perspectives for upscaling UA in Benin, and low- and middle-income countries in general. Section 5 concludes.

\section{Materials and Methods}

Below, we discussed the methods for the systematic literature review, the survey, and the in-depth interviews.

\subsection{Systematic Literature Review}

Prior to performing the systematic review, a general Google Scholar search was run to ensure that the search captured the appropriate studies. These articles and the systematic reviews by Poulsen, McNab, Clayton and Neff [13], Warren, Hawkesworth and Knai [14], and Korth, Stewart, Langer, Madinga, Da Silva, Zaranyika, van Rooyen and de Wet [15] were also used to collect the key terms and phrases for the search. Eligible articles were identified using five bibliographic databases: AGRICOLA EBSCO, CAB Abstracts, Science Direct, SCOPUS and Web of Science. The databases' search used Boolean operators to pair the primary keyword (urban agriculture) and its synonyms with each second keyword (financial security; food security) and their synonyms. To ensure novelty, only articles from 2013 to 2018 were included and the search was focused on low- and middle-income countries. Articles that were unavailable in English were excluded. The systematic search in the five databases resulted in a total of 2865 hits. The hand search resulted in the inclusion of an additional 13 articles. After deduplication and applying the critical assessment of the eligibility criteria, 26 articles were included in the systematic review (Figure 1). 


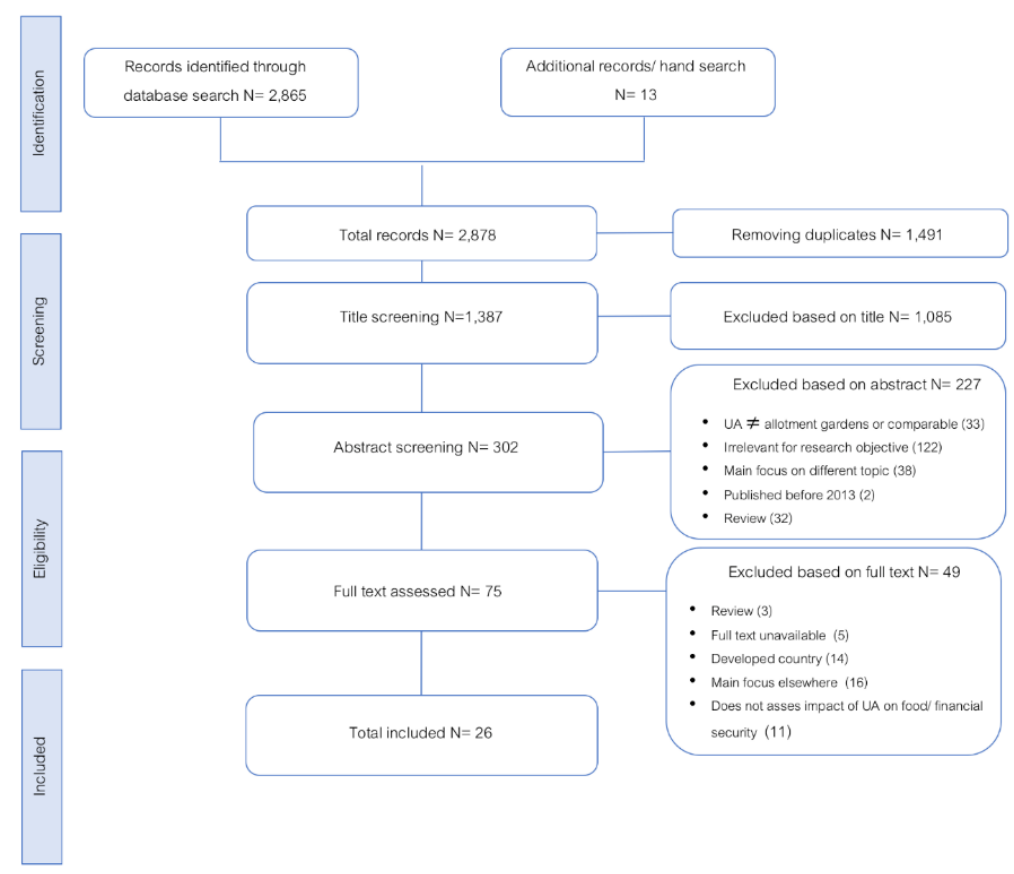

Figure 1. Guidelines of the systematic literature review. UA: Urban agriculture Data from the literature were extracted based on a pre-designed assessment tool and accompanying criteria primarily to determine the measured effect (positive or negative) of UA on food and financial security as well as social well-being. The effect of UA on social well-being was included in the analysis because we assumed that social well-being might be an additional motivation for policies to upscale UA. The included articles were also assessed along with the country where the study was conducted, the status (low- and middle-income) of the country, the drivers, the barriers, and the main conclusion. Further information regarding the search strategy, the assessment criteria, and the data extracted could be found in Van de Louw [20]. The results were used as a basis to classify and discuss all the identified constraints from the survey and the in-depth interviews.

\subsection{Survey among Experienced Gardeners}

A survey was conducted among 261 experienced gardeners in Cotonou and Porto-Novo, two cities in southern Benin (Figure 2) to explore the benefits, organization, and constraints for the development of urban allotment gardens, also referred to as urban gardens [10]. Therefore, the study investigated barriers that impede the implementation of allotment gardens by considering internal and external factors and interlinkages. Further details on the sampling, survey implementation, and data analysis were published in Houessou, et al. [21]. Here, we summarized the main steps. We used the formula of Yamane [22] to calculate the sample size from the study population of 828 urban gardeners. As the obtained number (270 respondents) exceeded 5\%, we used the Cochran [23] correction formula to calculate the corrected sample size (204 respondents). Then, we used two-stage stratified random sampling to determine the number of respondents per allotment garden, by multiplying the share of urban gardeners over the two cities and the share of urban gardeners over the allotment gardens per city. However, we decided to survey at least three members per allotment and adjusted the sample size, accordingly, giving a total of 261 respondents. 


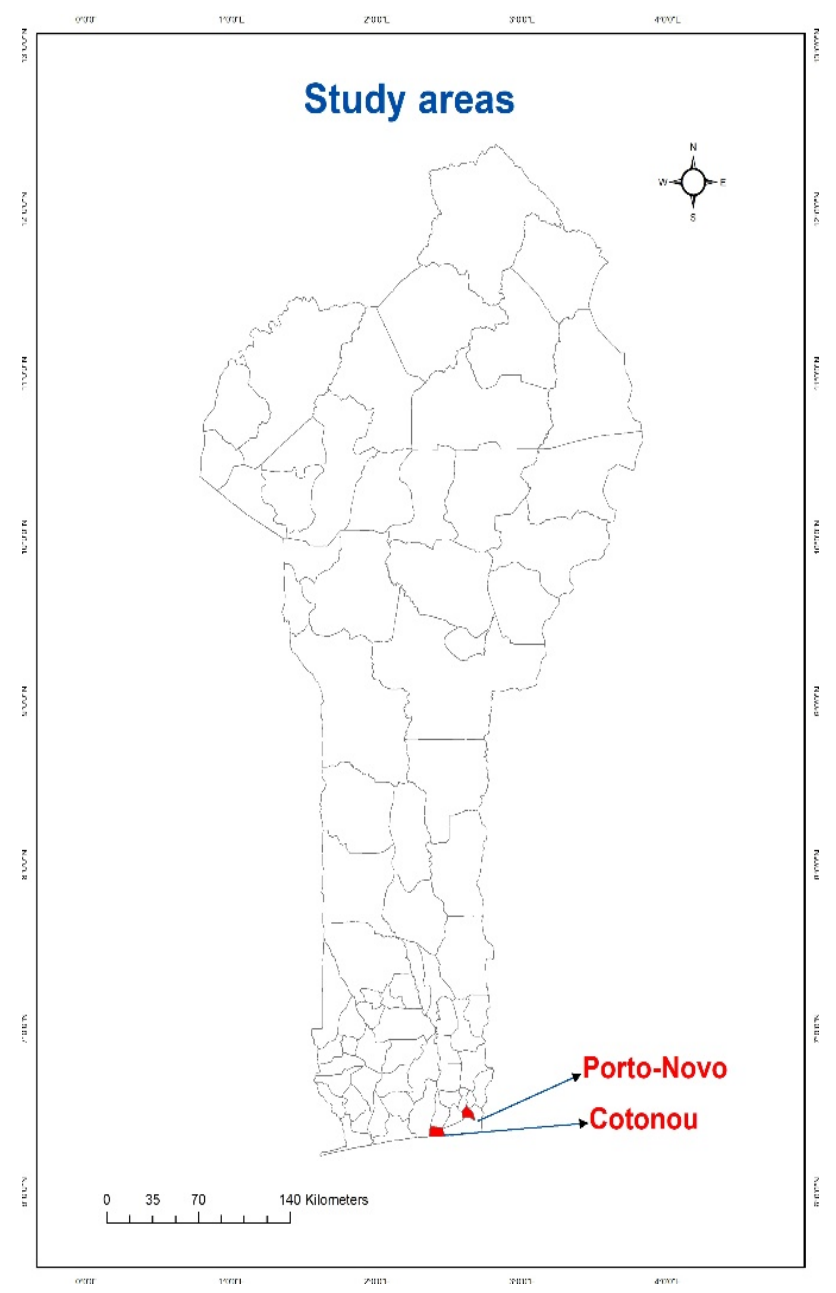

Figure 2. Study areas, https://www.diva-gis.org/gdata.

The survey used a spreadsheet format with validated lists in scroll-down menus as a standard response with dedicated fields for open answers to insert the collected data. The inserted data were, after that, stored in a vector format that facilitated further processing. Data processing and analysis used Minitab 14 for the descriptive statistics to present categorical answers as frequencies and numerical answers as means and quartiles. Afterwards, a focus group discussion was organized with gardeners and experts from the Ministry of Agriculture to verify and discuss the findings of this study. Detailed information on the processed data was stored in a working document [10] that is available for supplementary consultation. Furthermore, the discussion considered the most important constraints (first three columns from Table 1) as ranked by urban gardeners and classified them accordingly to the constraints identified in the systematic review.

\subsection{Semi-Structured Interviews}

Seven semi-structured interviews were conducted in March 2019 in Benin; six interviews with municipal and governmental policy officers, and one interview with a board member of the national association of urban gardeners. The stakeholders map for UA in this study was presented in Van de Louw [20]. The aim of the interviews was to perceive, from the policy perspective, the constraints that impede UA upscaling. The interviews used a discussion guide and lasted $57 \mathrm{~min}$ on average. The questions of the discussion guide were focused on political priority and familiarity with UA, constraints facing the implementation of UA and the possible solutions, and the political willingness to tackle encountered constraints. The perspectives were presumed to clarify the underlying motivations 
of local and national authorities. After informed consent was given, the interviews were audio recorded and iteratively transcribed to further adjust the discussion guide.

Regarding the analysis of the interview data, audio transcriptions were checked and validated by three researchers. Then, the thematic coding of the interviews was performed with the software Atlas.ti in an inductive manner [24] as follows. First, all the interviews were open-coded, allowing the key points of the data to be gathered. Second, the codes of comparable content were clustered into concepts. Lastly, the concepts were clustered in their turn into categories; the categories formed the basis of the conclusions from the interviews, exposing political constraints and their underlying causes that impede the upscaling of UA.

Table 1. Constraints ranking by the urban gardeners.

\begin{tabular}{cccccc}
\hline Could You Rank the Constraints for Gardening (from & $\mathbf{1}$ & (Most Important) & to & (Least Important))? \\
\hline Constraint (\%)/Rank & 1 & 2 & 3 & 4 & 5 \\
Land access and tenure insecurity & 60.2 & 21.5 & 06.5 & 03.5 & 04.6 \\
Lack of financial capital & 61.7 & 24.9 & 06.1 & 00.8 & 00.4 \\
Lack of access to clean and reliable water & 19.9 & 18.0 & 09.6 & 08.1 & 04.2 \\
High input costs & 11.9 & 21.8 & 16.5 & 09.6 & 05.0 \\
Market functioning & 06.5 & 20.3 & 24.1 & 05.0 & 03.5 \\
Relations with neighbors & 02.7 & 01.9 & 03.1 & 02.3 & 04.6 \\
Theft and robbery & 07.3 & 07.3 & 06.9 & 03.8 & 05.0 \\
Lack of farming skills & 13.8 & 15.7 & 20.7 & 12.6 & 06.9 \\
Labor shortage & 24.5 & 21.1 & 25.7 & 14.2 & 03.8 \\
Diseases & 08.4 & 11.1 & 08.8 & 08.1 & 08.8 \\
Lack of public authorities' commitment & 11.5 & 12.6 & 13.8 & 11.1 & 10.7 \\
\hline
\end{tabular}

\section{Results}

This section presents the results from the literature review, the survey with experienced gardeners and the in-depth interviews.

\subsection{The Literature Review}

Of the 26 studies, 22 were conducted in Africa: three studies in Asia and one in South America. Concerning the measured effects observed, 14 out of the 26 articles indicated a positive effect of UA on food security while two indicated a neutral or negative effect. With respect to the latter studies, the main argument was that UA does not positively impact on food security in its current status, but it could perhaps hold the potential to contribute. Concerning financial security, 17 included articles reported improved financial security due to UA, two articles a neutral effect and one study reported a negative effect. On well-being, eight articles reported an improvement in the social well-being of farmers attributable to practicing UA, while one article reported a negative effect. The positive effects mainly referred to increased social cohesion within the community $[25,26]$ and health benefits for those practicing UA $[27,28]$.

\section{- $\quad$ Barriers}

Five main barriers for UA development were found in the literature review. First, the lack of access to land and tenure insecurity were indicated as major barriers [25,29-35]. Indeed, not owning the land urban farmers worked on put them in a land insecurity situation, that impeded their investment, given the risk of non-compliance of mandatory reimbursements. For example, purchasing fertilizers does not guarantee higher harvests during unexpected dry spells; evidence learns that the tedious labor investments to create terraces only pays back after several years, long after lease contracts might expire.

Second, insufficient government support was a major barrier to urban cultivation [25,29-31,33-42]. Indeed, unclear urban policies on land use led to small or even the absence of investments as farmers 
forgo the risk of losing their relatively small income if authorities would claim the land and destroy their crops. Then, unsupportive governments made urban cultivation virtually impossible when land was attributed to land use types like industries and infrastructures.

Third, restricted market access was a constraint for urban farmers [25,27,35,38,42-45]. Market participation was difficult to urban farmers who were located far away from markets when transport costs make the commercialization of produce uninteresting. In addition, the lack of cooperation and therefore competition among gardeners resulted in weak capacities to bargain.

Fourth, the limited access to production factors such as fertilizer, clean water, knowledge and capital formed a constraint for farmers to develop their gardens productively $[25,27-32,34,35,38-40,42,44,46,47]$. It was indicated that restricted access in freshwater resources was a severe problem to practice urban farming. When, for irrigation purposes, freshwater necessarily had to be replaced with wastewater, customers might be afraid to be victimized by water-borne diseases $[38,42,46]$.

Last, inequality issues impeded the development of UA $[25,37,38,48]$, specifically when unequal access to productive resources downgraded women in their endeavors to practice urban farming and make a better living. For instance, in Nigeria, only males had assets to pledge for loans and cover the costs of acquiring land [48]. In addition, gender differences begot land leases to men over women, forcing women into smaller scaled plots, resulting in a lower income compared to men [37].

- Drivers

The reviewed literature indicated five main drivers in favor of UA development.

First, land access and ownership was mentioned as a strong driver to successful UA [29,31,36]. We noted a positive correlation between the access to and the ownership of land and the scale of the production system.

Second, farming efficiency was a driving factor towards UA implementation [26,31-33,38,43,47,49]. Indeed, improved production systems, where fewer inputs (fertilizer, water) were used, were a motivating factor for urban farmers to develop large farms [47]. In addition, specialization in dry season farming [43] and vertical farming by means of sack-gardening [26] enabled the inclusion of many more farmers and increased production in cities.

Third, policy support was found to boost the development of UA [25,27-29,33]. For example, in Tanzania, the policies allowed farmers to freely organize themselves in interest groups that could exert pressure on policymakers for support to farmers [25]. Policy support in land allocation to agriculture in cities was also found to enable the development of UA in Vietnam [33]. In addition, perceived benefits in terms of income generation and contribution to food security as well as sound institutional arrangements motivated policy support towards UA [28,29].

Fourth, a sound internal organization and cooperation between farmers positively influenced UA development $[28,38,44,47,48,50]$. Organizing working groups and collaboration among farmers improved farming skills and production levels. This also improved their access to funding and organized joint ventures to access markets.

Finally, the close proximity to a market was considered an important factor for a broad implementation of UA $[30,31,35,43]$. Indeed, closer proximity resulted in cost advantages for the producers and enhanced their income due to the decrease in travelling costs, the better knowledge of market prices and a lower risk in the transportation of highly perishable goods.

\subsection{The Survey}

\section{- $\quad$ Barriers}

Urban gardeners indicated several constraints impeding their activities (Figure 3). First, almost all $(97 \%)$ of the surveyed gardeners considered land access and tenure insecurity as a constraint for their urban gardening activities. The main reasons included land unavailability $(47 \%)$, the lack of policy regulation $(30 \%)$, the difficulty in leasing land $(20 \%)$ and others (a combination of the aforementioned 
reasons as well as a lack of security with the landlord and a lack of space). However, the majority (62\%) of gardeners indicated that municipalities are not willing to solve the land access issue. Second, a high number of gardeners (94\%) indicated the lack of financial capital as a constraint for gardening. The main reasons cited included the lack of credit for agricultural activities (33\%), the high interest rates of financial institutions $(29 \%)$, the lack of collateral to obtain credit $(24 \%)$, the lack of a deferred period for reimbursements $(3 \%)$ and others $(10 \%)$, such as the absence of an agricultural bank and the difficulty in obtaining credit. Third, most gardeners $(64 \%)$ considered the lack of access to clean and reliable water as a constraint for gardening. The main reasons included the unavailability of equipment for irrigation $(70 \%)$, the pollution of shallow water in wells $(15 \%)$, seasonal rainfall patterns $(11 \%)$ and others $(4 \%)$, such as no control over water, floods, and leaching in rainy season.

Fourth, a majority $(68 \%)$ of the gardeners considered the high costs of inputs as a constraint for gardening. The main reasons were the frequent rupture of inputs such as fertilizer and pesticide $(52 \%)$, the shortage of input providers on the market $(42 \%)$, and others $(6 \%$,), such as the lack of a government subsidy, the market monopoly and the lack of money.

Fifth, more than two-thirds (67\%) considered market functioning as a constraint to gardening. The reasons were the low prices in general (74\%), unreliable relationships with traders ( $9 \%$ ), the distance from farms to markets $(4 \%)$, unreliable relationships with brokers $(1 \%)$, and others $(12 \%)$ such as the lack of clients, the lack of control over vegetable imports, the bias against local produce among customers, as well as the lack of contracts with hotels, restaurants and consumers. Sixth, only $5 \%$ of the gardeners considered their partnership with neighbors (gardeners or people on the immediate outskirts) as a constraint. Seventh, about three-quarters (72\%) of the gardeners considered the lack of farming skills (improved technics and pest management) as a constraint for gardening. Eighth, a high number of gardeners $(96 \%)$ considered the lack of commitment from public authorities as a constraint for gardening. Ninth, about half $(48 \%)$ of the gardeners considered labor shortage as a constraint to gardening, but only $5 \%$ of them thought that the labor shortage could be addressed. Tenth, and last, theft and robbery (36\%) and diseases such as malaria and diarrhea $(60 \%)$ were two other factors considered by the gardeners as constraints to gardening.

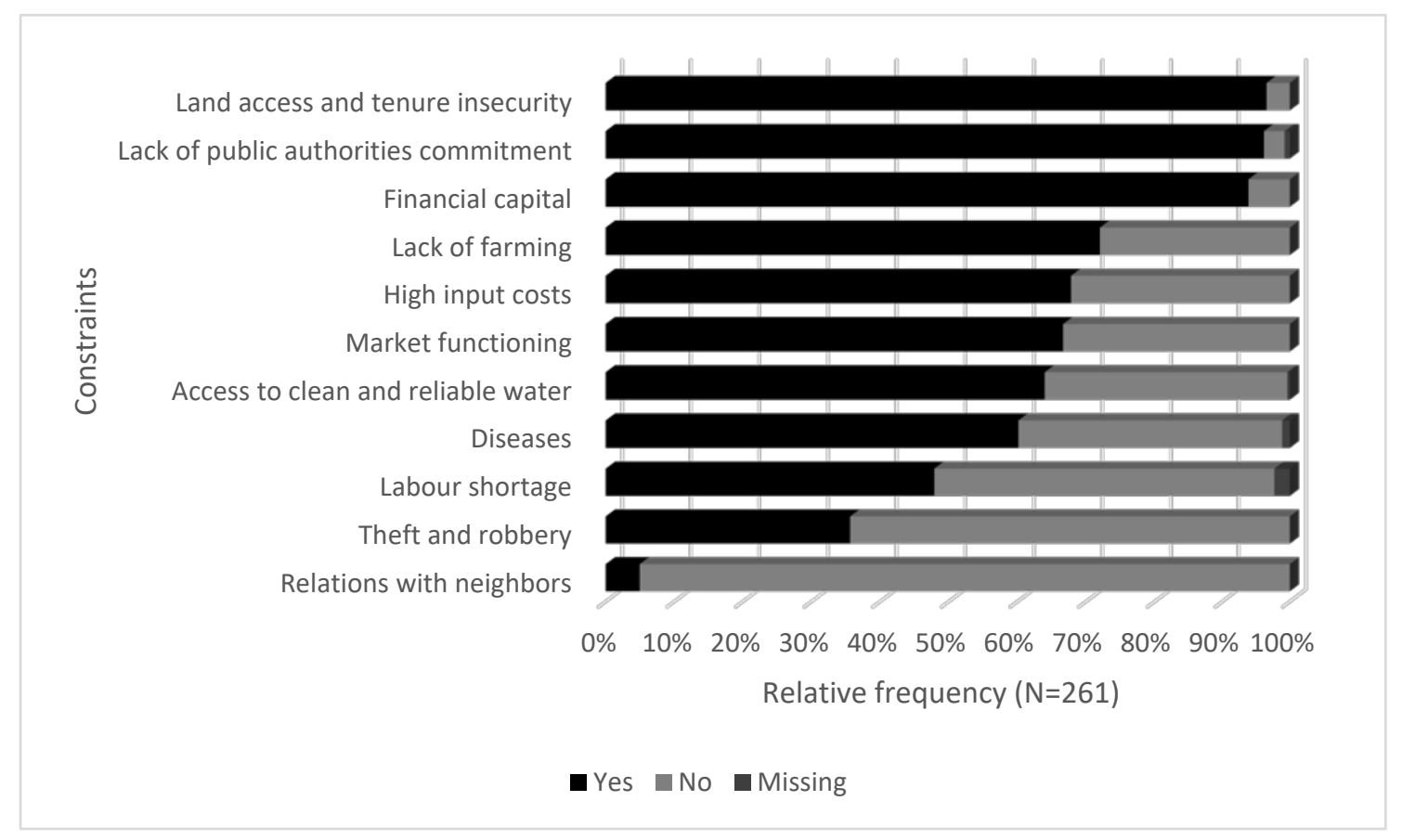

Figure 3. Perspectives of the urban gardeners on the constraints facing UA development. 
To prioritize the constraints, the gardeners scored them from the most important to the least important (Table 1). Land access and tenure insecurity, lack of financial capital and the lack of public authorities' commitment were the first set of three constraints identified by the gardeners. The second set of constraints comprised the lack of access to clean and reliable water and the high cost of inputs. The third set included the market functioning, the lack of farming skills and to some extent diseases. The last set of constraints covered the relationships with neighbors, theft and robbery, and labor shortage.

\section{- $\quad$ Drivers}

Against the identified constraints, the gardeners suggested solutions that might drive the development of UA. First, regarding the land access and tenure insecurity, possible solutions included the promotion of intercommunal partnership to provide cities with large areas for UA $(39 \%)$, the enhancement of urban planning mainstreaming zoning $(32 \%)$, and negotiating with public and private institutions to lease their open spaces for an extended period $(20 \%)$.

Second, regarding the lack of financial capital, gardeners suggested to adapt loan access conditions (collateral and deferred period for reimbursements) to the agricultural sector $(42 \%)$, to reduce the financial institutions' interest rates $(28 \%)$, and encourage cooperative formation between the gardeners to access loans $(23 \%)$, and others such as the creation of an agricultural bank $(6 \%)$.

Third, to tackle the lack of access to clean and reliable water, the gardeners suggested that policies support farmers in accessing loans to purchase water equipment $(69 \%)$, in securing land tenure so that gardeners can invest in irrigation or water de-pollution $(29 \%)$, and others $(2 \%)$ such as conserving nature.

Fourth, among the possible solutions against the high costs of inputs, the gardeners suggested to enable a more business-oriented approach, reducing the input costs $(60 \%)$, regulating input costs through policy instruments such as customs reduction $(30 \%)$, and others $(7 \%)$ such as installing a local manufacturing unit in the country.

Fifth, the suggested solutions to improve market functioning included the access to markets in other cities (31\%), the avoidance of fixed-price arrangements (23\%), making direct contact with traders $(14 \%)$, the access to export markets $(6 \%)$, and others $(24 \%)$, such as price regulation, the avoidance of vegetable imports, and the promotion of local consumption.

Sixth, although few gardeners considered their partnership with neighbors as a constraint, they thought that the relationship with neighbors could be improved most efficiently through negotiations $(69 \%)$ and better agreements on the use of land/water $(31 \%)$. They also indicated that improved conflict resolution should be organized by the management committee board $(69 \%)$, local authorities (23\%) and amicably by the affected parties $(8 \%)$.

Seventh, concerning the lack of farming skills, gardeners indicated that capacity-building programs $(58 \%)$, the customization of extension services to the needs and comprehension levels of gardeners $(36 \%)$ or both $(1 \%)$ are possible solutions to the issue.

Eighth, to tackle the issue of a lack of commitment from public authorities, the gardeners suggested the financial support to UA $(72 \%)$, the legitimization of UA (21\%), and others $(4 \%)$ such as setting up a discussion platform between the government and gardeners.

Ninth, and last, although few gardeners thought that labor shortage could be addressed, they suggested raising awareness among youth of the benefits of gardening and the need to use modern technology in gardening activities.

\subsection{The In-Depth Interviews}

- Barriers

All interviewees indicated the unavailability of land as the main constraint for UA development. The lack of access to land resulted in tenure insecurity, as farmers were uninformed about when the 
land would be claimed. Land unavailability was attributed to rapid urbanization in combination with a lack of reservation of land for UA, though planned in development plans. Especially in Benin, where land is privately owned, purchasing land by the government for UA was perceived as too costly because its benefits and profitability were not fully recognized by those who had the power to make change.

Then, natural constraints like pests and climate change were mentioned as constraints to UA. The reason was that the pesticides required to combat pests in vegetable production were not available or prohibited by the government due to soil contamination and health risks. One of the interviewees exemplified: "I worked in Cotonou before and there was an area where people were exploiting and just one day a French investor bought all the land and the people were chased away. There were still crops growing, almost ready to be harvested, but they did not care and ruined everything".

Furthermore, UA was a low priority for policies. The political priority of UA was determined by two factors: the responsibility and the perceived benefits. For instance, who should be held responsible for the success of UA appeared unclear because some interviewees stressed the government's responsibility to allocate land to ensure food security for its citizens, while others claimed that farmers were entrepreneurs and were therefore responsible for their own success. In addition, although the benefits of UA, such as the contribution to food security, healthy and affordable food, income and employment, and social cohesion were indicated, about half of the interviewees claimed that the benefits were largely unperceived by the government; resulting in the unwillingness to make actual changes. Moreover, it was unclear among interviewees which institutions should be mandated to bring about changes in favor of UA.

The prevailing situation showed that although urban development plans were in place, they were not enforced. Especially, urban planning that allocated land for various purposes was unknown by communities and ignored by authorities. Therefore, drawing up development plans and policy implications appeared ineffective, as it required a strong political will to enforce them. An interviewee also argued that the status quo might be explained by the unperceived benefits of investing in UA by the government. He further claimed that on top of the benefits for the economy, UA can bring in money as well:

"In terms, people will pay taxes, but before they pay taxes, they should experience support so that they are willing to pay taxes. If you do not support them, they are not willing to pay taxes. So, from both sides trust should be gained to help each other" (member of the National Agency for Territorial Development).

- Drivers

Many changes were required to overcome the constraints that were in place. First, a strict enforcement and control of policies and development plans was indicated as essential to improve land allocation to UA and prevent the uncontrolled urban sprawl. To that end, policymakers were indicated as important players to ensure the policies' enforcement.

Then, the interviewees indicated that academic support was needed to provide a decision-support tool for the policymakers to allocate land to UA. Another indicated role for researchers was to provide improved farming technologies and measure the impact of UA on food and financial security, the livelihoods of the urban poor, and economic growth.

Furthermore, there was the need to inform and convince decision-makers with evidence-informed solutions to impact the political agenda. For instance, the government was convinced about the potential of cash crops such as cotton and cashew, and therefore, they made huge investments in these products. Similarly, the interviewees argued that convincing the government to support UA depended on how they were convinced of the profitability of the sector. A proper means of collaboration between urban farmers and the government was also required to enhance political priority. If the urban farmers could demonstrate the positive impact of UA on their lives, political priority would increase. Platforms 
to establish such collaboration existed but were not functioning accordingly, hence the need to rebirth such platforms.

The interviewees further made suggestions to overcome the existing political constraints as follows: land lease contracts, reserving all left-over land and vertical farming. Regarding land lease contracts, two types of contracts were suggested: 5-year and 10-year lease contracts that allow urban farmers to temporarily utilize urban land while simultaneously ensuring private owners their property. Concerning the reservation of yet available land, mainly in peri-urban areas, interviewees suggested to enforce the development plans in place. In fact, on paper, the land was already reserved as green space but in practice, this was not the case. Therefore, the efforts should endeavor to keep and allocate the remainder to UA. Last, vertical farming was proposed to explore the possibilities of producing food on less space. In terms of vertical farming, mainly hydroponics was proposed to reduce the use of inputs and the increase yields. However, the interviewees suggested that hydroponics should be researched to propose how it could be adapted to local conditions.

\section{Discussion}

This study used a three-pronged approach to summarize the evidence regarding the constraints facing the development of UA in Benin. The approach is relevant for two reasons. First, using standard systematic review procedures to explore the push and pull factors for UA in low- and middle-income countries was indicated to present up-to-date evidence and perspectives for policy making and practice [51]. Second, developing a country case study enables in-depth exploration, from a policy and practice perspective, of the key issues impeding broad UA implementation. The approach is sound and innovative as the three congruent components—systematic review, survey among urban gardeners, and interviews among authorities-complement each other as follows. The systematic review brought an international perspective, the survey consulted urban gardeners who are direct actors in Benin on the restrictions and opportunities at the field level, while the interviews with experts from local and national government provided insights about the explicit political constraints. Altogether, the findings generated a broad spectrum of prevailing constraints in the sector and how policies could be incentivized to take necessary actions. The soundness of the approach is corroborated by Artmann and Sartison [18] who indicated in their systematic literature review the important drivers and constraints of UA implementation in the Global North that regardless of the number of times drivers and constraints may have been cited in a literature review, context-specific cases might prove valuable for policy making. For instance, in addition to a systematic literature review conducted on factors that support or obstruct the development of urban community gardens in some high-income countries, Wesener, Fox-Kämper, Sondermann and Münderlein [19] consulted the perspectives of urban gardeners and external experts in New Zealand and Germany to inform a country-specific knowledge base and thereby, relevant policy making.

\subsection{Constraints Facing UA Development}

The review indicated five main barriers to UA upscaling: the lack of land and tenure insecurity, insufficient government support, restricted market access, the limited access to productive factors and inequality issues. However, the barriers do not have the same importance; the limited access to productive factors, insufficient government policy, and the lack of land and tenure insecurity appear to be the most cited and highly prominent exponents. Land insecurity is a major barrier that is reducing the potential of UA. Hence, when land is available, the support of policies becomes instrumental to secure tenure for further urban garden development. For instance, even in densely urbanized areas, there may be a high amount of land that can be used either temporarily (for land reserves) or permanently (for green areas), that is, if there is a strong political will. In addition, allocating land to urban gardening would take various conditions into account, including the vicinity of the market that can improve market access for farmers. The two examples showed that most barriers are linked and can be tackled together if there is a clearly defined roadmap that is taken up by policies. 
The review also showed that there are five main drivers that may propel the development of UA: land access and ownership, farming efficiency, policy support, cooperation among gardeners and access to the market. Efficient farming due to improved technologies and cooperation among gardeners were the most cited among the drivers. The two drivers were mostly dependent on the choice of urban farmers when developing their gardens. For instance, the farmers can choose to either modify their production systems (dry season farming or vertical farming) and improve yields and incomes, or make joint ventures with peers and improve their bargaining power and sales. Although the rest of drivers was less cited, they are crucial to even start farming in cities. For instance, without land, there is no way to farm within cities. Therefore, their absence is problematic to the development of UA.

Furthermore, it can be noted that most barriers are the absence of the aforementioned drivers. For instance, while land access is playing a major role in upscaling UA, its absence mirrors the opposite role. The same is true for efficient farming and the limited access to productive factors, policy support and insufficient governmental support, as well as vicinity to market and restricted market access. Therefore, the drivers and barriers are two faces of the same coin and we posit that policy support has a pivotal role in addressing the constraints facing the upscaling of UA, for example, by allocating land to UA. In their study, Wesener, Fox-Kämper, Sondermann and Münderlein [19] also indicated that there are many "two-sided" factors, e.g., funding, that may enable, if given, or obstruct, if missing, UA implementation.

The survey explored the challenges encountered by urban gardeners in Benin and showed that the identified constraints nicely fit into the main constraints of the systematic review. Indeed, beyond the lack of land, lack of public authorities' commitment and market functioning, the remainder (lack of financial capital, lack of access to clean and reliable water, high input costs, and the lack of farming skills) could be grouped into the limited access to productive factors. The findings showed that land access and tenure insecurity, the lack of financial capital, and the lack of public authorities' commitment are the three major constraints to UA, and that decision makers are not willing to solve the problems. This finding calls for advocacy at the local and central authority levels to gain their attention on UA and help them address the challenges. Therefore, the gardeners made three recommendations for policies: the promotion of intercommunal partnerships to provide cities with large areas of land for UA, the enhancement of urban planning that mainstreams gardening as a compelling land type use, and the constitution of a guarantee fund to encourage financial institutions to finance agriculture. However, gardeners are also encouraged to improve their cooperation to make joint ventures such as accessing loans and the market. Furthermore, the gardeners showed that the lack of access to clean and reliable water, high input costs, market functioning, and the lack of farming skills hinder gardening activity. Solutions to deal with these constrains go beyond the individual and require that policies deliver the following actions: providing and securing land for farmers to allow investment in irrigation; regulating the industry of inputs through de-monopolization and customs reduction, as well as the vegetable market by reducing imports and promoting local produce; and customizing capacity-building and extension programs to meet the needs of gardeners. Hence, we posit that the integration of the solutions into policy agendas is instrumental to create an enabling environment for the expansion of UA, but at the condition to improve political unwillingness. Although the survey focused on allotment gardens, we assume that the findings are also relevant to other forms of UA (home gardening, individually owned farms). Indeed, regardless of the place of production, the other forms of UA are also present in the same food value chains and the experience shows that they buy inputs and contribute to the same food markets.

In their review of the important drivers and constraints of UA implementation in the Global North, Artmann and Sartison [18] compared the factors among the institutional, social, economic, ecological, spatial, and technical categories. Their findings indicated that community participation, policy regulations, available funding resources, nature protection, securing space for $\mathrm{UA}$, and efficient management methods were the most cited drivers. However, regarding the barriers, the lack of governmental support, lack of community support, investment costs, soil contamination, limited space 
for UA, and infrastructural constraints were the most cited. Their findings also confirm that most drivers and barriers are two-sided factors, regardless of the geographical zone. In addition, their findings hold true our assumption that there are some spatial differences among the drivers and barriers of UA implementation. For instance, while a lack of land is the most important barrier in Benin and lowand middle-income countries in general, this factor is low-prioritized in the Global North. However, regardless of the region, insufficient government support is found to be of utmost importance to help address the constraints facing UA development. Hence, trying to understand what constrains political willingness from investing in UA is relevant.

\subsection{Solutions Improving Political Willingness}

To delve into what constrains political engagement in supporting UA, the interviews learnt from the policy perspective and nicely showed that policy makers indicated the unavailability of land as the main constraint for UA development in Benin. However, although policy makers attribute land unavailability to rapid urbanization in combination with a lack of reservation of land for urban gardening in development plans, they are not willing to make actual change to the prevailing situation. The status quo of unwillingness is explained by two reasons. First, the benefits of investing in UA are unperceived by the government. This reason is further explained by the fact that the government of Benin makes huge investments in cotton and cashew because they are convinced of the potential of these crops in the improvement of the livelihoods of farmers and the economy. Therefore, convincing the government to support UA depends on how they are convinced of the profitability of UA on livelihoods and the economy; hence the need to conduct robust research that would inform agricultural policies. Second, urban development plans are not enforced. Indeed, although there is urban planning that allocates land for various purposes including urban gardening, there are no compelling rules to ensure its enforcement. Therefore, strict enforcement and control policies and development plans are instrumental to improve land allocation to UA and prevent uncontrolled urban sprawl.

However, implementing the proposed solutions is not without difficulty. First, land allocation to UA is not an easy task and requires that academics design a decision-support tool. Thus, vacant land could be allocated through lease contracts. Then, as land area is continuously shrinking, there is the need to improve farming technologies and produce more food on less space; alternative agricultural techniques like hydroponics offer that possibility but in a first attempt need to be researched and adapted to local conditions.

The transdisciplinary approach used in the research makes it sound to create novel findings to the body of knowledge as the stakeholders' experience was added to a systematic review on the identified constraints that impede the upscaling of UA. Then, the systematic approach and the number of databases searched for the review allowed us to identify a wide variety of studies available on the topic. This study also set a time period (2013-2018) that was recent and hence relevant to the current nature of UA. However, this study has a limitation. Indeed, the number of semi-structured interviews $(\mathrm{N}=7)$ seems small and a larger sample size could have increased the data validity. However, the number of interviewees is not unusual for semi-structured in-depth interviews (e.g., Crouch and McKenzie [52]) that tap from individual well informed experts that allow us to obtain a deeper understanding of the processes behind UA development.

\section{Conclusions}

Our study assessed what the key constraints to the expansion of UA are in Benin. To answer, we used a three-pronged approach combined with standard systematic review procedures, responses from a survey among gardeners, and interviews with stakeholders. The constraints identified from the systematic review were used to classify and discuss the results of the survey and the interviews. We found that the drivers and barriers are two faces of the same coin, and that there are five main constraints to UA: the lack of land and tenure insecurity, insufficient government support, restricted market access, limited access to productive factors, and inequality issues. On top of that, we found 
evidence that most barriers are linked and could be tackled together if there is a clearly defined roadmap that is followed by policies, but the current political unwillingness may be explained by two reasons: the unperceived benefits of investing in UA and the lack of enforcement of urban development plans that allocate land for various purposes including urban gardening. Although, we are calling policy attention to the enforcement of urban planning and investment in UA, there is a need to conduct further research on the following questions: what is the impact of urban gardening on the livelihoods of farmers? How to design a land allocation tool in urban areas? Finally, how to adapt hydroponics to local conditions?

Author Contributions: Conceptualization, M.D.H. and B.G.J.S.S.; methodology, M.D.H. and M.v.d.L.; software, M.D.H. and M.v.d.L.; validation, M.D.H., M.v.d.L. and B.G.J.S.S.; formal analysis, M.D.H. and M.v.d.L.; investigation, M.D.H. and M.v.d.L.; data curation, M.D.H. and M.v.d.L.; writing—original draft preparation, M.D.H. and M.v.d.L.; writing - review and editing, B.G.J.S.S.; supervision, M.D.H. and B.G.J.S.S.; funding acquisition, M.D.H. and B.G.J.S.S. All authors have read and agreed to the published version of the manuscript.

Funding: This research was funded by Nederlandse Organisatie voor Wetenschappelijk Onderzoek, File no: 08.260.302 and Nuffic: R/003248.01.

Conflicts of Interest: The authors declare no conflict of interest.

\section{References}

1. GFFA. How to Feed Our Cities? - Agriculture and Rural Areas in an Era of Urbanisation. In Proceedings of the Global Forum for Food and Agriculture 2016: Communiqué 8th Berlin Agriculture Ministers' Summit, Berlin, Germany, 16 January 2016; p. 6.

2. Ravallion, M.; Chen, S.; Sangraula, P. New evidence on the urbanization of global poverty. Popul. Dev. Rev. 2007, 33, 667-701. [CrossRef]

3. FAO; IFAD; UNICEF; WFP. The State of Food Security and Nutrition in the World 2017. Building Resilience for Peace and Food Security; FAO: Rome, Italy, 2017.

4. FAO. Urban Agriculture: FAO's Role in Urban Agriculture. Available online: http://www.fao.org/urbanagriculture/en/ (accessed on 21 November 2019).

5. Karanja, N.; Njenga, M. State of the World 2011: Innovations that Nourish the Planet; Worldwatch Institute: Washington, DC, USA, 2011; Brief on Chapter 10, Feeding the Cities.

6. Dubbeling, M.; Zeeuw, H.D.; Veenhuizen, R.V. Cities, Poverty and Food: Multi-stakeholder Policy and Planning in Urban Agriculture; Practical Action Publishing: Warwickshire, UK, 2010.

7. Drescher, A.; Holmer, R.; Glaser, R.; Richert, C. Understanding urban and peri-urban vegetable production and marketing systems through GIS-based community food mapping as part of an interactive collaborative research environment in Southeast Asia-An outlook. In SEAVEG 2012: High Value Vegetables in Southeast Asia: Production, Supply and Demand; AVRDC, The World vegetable Center: Chiang Mai, Thailand, 2013; p. 272.

8. Novo, M.G.; Murphy, C. Urban agriculture in the city of Havana: A popular response to a crisis. In Growing Cities, Growing Food: Urban Agriculture on the Policy Agenda; Bakker, N., Dubbeling, M., Gündel, S., Sabel-Koshella, U., de Zeeuw, H., Eds.; Zentralstelle für Ernährung und Landwirtschaft (ZEL): Feldafing, Germany, 2000; pp. 329-346.

9. Taiwo, O.J. Determinants of peri-urban and urban agricultural locational choice behaviour in Lagos, Nigeria. Land Use Policy 2014, 39, 320-330. [CrossRef]

10. Houessou, D.; Thoto, F.; Sonneveld, B.; Aoudji, A.; Dossou, S.; Agbandou, B. Urban Agriculture in Benin: How can Policy Support Gardeners? Research 2019, 80. [CrossRef]

11. De Zeeuw, H. The development of Urban Agriculture; some lessons learnt. In Proceedings of the Keynote Paper for the International Conference Urban Agriculture, Agri-Tourism and City Region Development, Beijing, China, 10-14 October 2004. RUAF.

12. FAO. Growing Greener Cities in Africa: First Status Report on Urban and Peri-Urban Horticulture in Africa; Food and Agriculture Organization of the United Nations: Rome, Italy, 2012.

13. Poulsen, M.N.; McNab, P.R.; Clayton, M.L.; Neff, R.A. A systematic review of urban agriculture and food security impacts in low-income countries. Food Policy 2015, 55, 131-146. [CrossRef] 
14. Warren, E.; Hawkesworth, S.; Knai, C. Investigating the association between urban agriculture and food security, dietary diversity, and nutritional status: A systematic literature review. Food Policy 2015, 53, 54-66. [CrossRef]

15. Korth, M.; Stewart, R.; Langer, L.; Madinga, N.; Da Silva, N.R.; Zaranyika, H.; van Rooyen, C.; de Wet, T. What are the impacts of urban agriculture programs on food security in low and middle-income countries: A systematic review. Environ. Evid. 2014, 3, 21. [CrossRef]

16. INSAE. RGPH4: Que Retenir des Effectifs de Population en 2013? Institut National de la Statistiqye et de l'Analyse Economique: Cotonou, Bénin, 2015; p. 33.

17. World Bank. Urban Population (\% of Total Population)-Benin. United Nations Population Division. World Urbanization Prospects: 2018 Revision. Available online: https://data.worldbank.org/indicator/SP. URB.TOTL.IN.ZS?locations=BJ (accessed on 16 May 2020).

18. Artmann, M.; Sartison, K. The role of urban agriculture as a nature-based solution: A review for developing a systemic assessment framework. Sustainability 2018, 10, 1937. [CrossRef]

19. Wesener, A.; Fox-Kämper, R.; Sondermann, M.; Münderlein, D. Placemaking in action: Factors that support or obstruct the development of urban community gardens. Sustainability 2020, 12, 657. [CrossRef]

20. Van de Louw, M. Urban Agriculture: Drivers and Barriers towards Food and Economic Security; Vrije Universiteit: Amsterdam, The Netherlands, 2019.

21. Houessou, D.M.; Sonneveld, B.G.; Aoudji, A.K.; Thoto, F.S.; Dossou, S.A.; Snelder, D.J.; Adegbidi, A.A.; De Cock Buning, T. How to transition from cooperations to cooperatives: A case study of the factors impacting the organization of urban gardeners in Benin. Sustainability 2019, 11, 4528. [CrossRef]

22. Yamane, T. Statistics: An Introductory Analysis; Harper and Row: New York, NY, USA, 1973.

23. Cochran, W.G. Sampling Techniques, 3rd ed.; Wiley: New York, NY, USA, 1977.

24. Corbin, J.; Strauss, A. Qualitative sociology. Cronstrom, (2012): “A Historical Odyssey: What Is Qlikview 1990. Available online: http://www.zfs-online.org/index.php/zfs/article/viewFile/2741/2278 (accessed on 1 May 2018).

25. Bonatti, M.; Homem, L.H.; Graef, F.; Mbwana, H.A.; Rybak, C.; Lana, M.; Sieber, S. Social organization, constraints and opportunities for kitchen garden implementation: ScalA and ScalA-FS assessment tools in Morogoro and Dodoma, Tanzania. Food Secur. 2017, 9, 1299-1308. [CrossRef]

26. Gallaher, C.M.; Kerr, J.M.; Njenga, M.; Karanja, N.K.; WinklerPrins, A.M. Urban agriculture, social capital, and food security in the Kibera slums of Nairobi, Kenya. Agric. Hum. Values 2013, 30, 389-404. [CrossRef]

27. Battersby, J.; Marshak, M. Growing communities: Integrating the social and economic benefits of urban agriculture in Cape Town. Urban Forum 2014, 25, 447-461. [CrossRef]

28. d'Haese, M.; Vink, N.; Nkunzimana, T.; Van Damme, E.; Van Rooyen, J.; Remaut, A.-M.; Staelens, L.; $\mathrm{d}^{\prime}$ Haese, L. Improving food security in the rural areas of KwaZulu-Natal province, South Africa: Too little, too slow. Dev. South. Afr. 2013, 30, 468-490. [CrossRef]

29. Halloran, A.; Magid, J. Planning the unplanned: Incorporating agriculture as an urban land use into the Dar es Salaam master plan and beyond. Environ. Urban. 2013, 25, 541-558. [CrossRef]

30. Magidimisha, H.H.; Chipungu, L.; Awuorh-Hayangah, R. Challenges and strategies among the poor: Focus on urban agriculture in KwaMashu, Durban, South Africa. J. Agric. Food Syst. Community Dev. 2013, 3, 109-126. [CrossRef]

31. Moyo, P. Urban agriculture and poverty mitigation in Zimbabwe: Prospects and obstacles in Bulawayo townships. J. Hum. Ecol. 2013, 42, 125-133. [CrossRef]

32. de Medeiros, N.S.A.; do Carmo, D.L.; Priore, S.E.; Santos, R.H.S.; Pinto, C.A. Food security and edible plant cultivation in the urban gardens of socially disadvantaged families in the municipality of Viçosa, Minas Gerais, Brazil. Environ. Dev. Sustain. 2019, 21, 1171-1184. [CrossRef]

33. Pulliat, G. Food securitization and urban agriculture in Hanoi (Vietnam). Artic.-J. Urban Res. 2015. [CrossRef]

34. Chagomoka, T.; Drescher, A.; Glaser, R.; Marschner, B.; Schlesinger, J.; Abizari, A.-R.; Karg, H.; Nyandoro, G. Urban and peri-urban agriculture and its implication on food and nutrition insecurity in northern Ghana: A socio-spatial analysis along the urban-rural continuum. Popul. Environ. 2018, 40, 27-46. [CrossRef]

35. Assefa, A. Constraints and opportunities in peri-urban and urban agriculture system in Addis Ababa, Ethiopia. Afr. J. Rural Dev. 2016, 1, 107.

36. Masvaure, S. Coping with food poverty in cities: The case of urban agriculture in Glen Norah Township in Harare. Renew. Agric. Food Syst. 2016, 31, 202-213. [CrossRef] 
37. Frayne, B.; McCordic, C.; Shilomboleni, H. Growing out of poverty: Does urban agriculture contribute to household food security in Southern African cities? Urban Forum 2014, 25, 177-189. [CrossRef]

38. Cadzow, H.; Binns, T. Empowering Freetown's women farmers. Appl. Geogr. 2016, 74, 1-11. [CrossRef]

39. Lynch, K.; Maconachie, R.; Binns, T.; Tengbe, P.; Bangura, K. Meeting the urban challenge? Urban agriculture and food security in post-conflict Freetown, Sierra Leone. Appl. Geogr. 2013, 36, 31-39. [CrossRef]

40. Smart, J.; Nel, E.; Binns, T. Economic crisis and food security in Africa: Exploring the significance of urban agriculture in Zambia's Copperbelt province. Geoforum 2015, 65, 37-45. [CrossRef]

41. Indraprahasta, G.S. The potential of urban agriculture development in Jakarta. Procedia Environ. Sci. 2013, 17, 11-19. [CrossRef]

42. Nchanji, E.B. Sustainable Urban Agriculture in Ghana: What Governance System Works? Sustainability 2017, 9, 2090. [CrossRef]

43. Akintayo, O.; Oyewole, B. Productive Potential of Urban Agriculture Towards Food Security: Evidence from Southwest Nigeria. In Sustainable Food Security in the Era of Local and Global Environmental Change; Behnassi, M., Pollmann, O., Kissinger, G., Eds.; Springer: Dordrecht, Germany, 2013; pp. 159-174.

44. Bernard, C.; Cephas, M.; John, B. Community gardens and food security in rural livelihood development: The case of entrepreneurial and market gardens in Mberengwa, Zimbabwe. Russ. J. Agric. Socio-Econ. Sci. 2013, 13.1, 8-17.

45. Crush, J. The prevalence of urban food production and food insecurity in Southern African cities. Acta Hortic. 2014, 227-238. [CrossRef]

46. Omondi, S.O.; Oluoch-Kosura, W.; Jirström, M. The role of urban-based agriculture on food security: Kenyan case studies. Geogr. Res. 2017, 55, 231-241. [CrossRef]

47. Dyer, M.; Mills, R.; Conradie, B.; Piesse, J. Harvest of Hope: The contribution of peri-urban agriculture in South African townships. Agrekon 2015, 54, 73-86. [CrossRef]

48. Adenegan, K.O.; Balogun, O.L.; Yusuf, T.O. Initial household assets and profitability of urban farming. Int. J. Veg. Sci. 2016, 22, 153-160. [CrossRef]

49. Wan, N.-F.; Cai, Y.-M.; Shen, Y.-J.; Ji, X.-Y.; Wu, X.-W.; Zheng, X.-R.; Cheng, W.; Li, J.; Jiang, Y.-P.; Chen, X. Increasing plant diversity with border crops reduces insecticide use and increases crop yield in urban agriculture. Elife 2018, 7, e35103. [CrossRef] [PubMed]

50. Olivier, D.W.; Heinecken, L. The personal and social benefits of urban agriculture experienced by cultivators on the Cape Flats. Dev. South. Afr. 2017, 34, 168-181. [CrossRef]

51. Liberati, A.; Altman, D.G.; Tetzlaff, J.; Mulrow, C.; Gøtzsche, P.C.; Ioannidis, J.P.; Clarke, M.; Devereaux, P.J.; Kleijnen, J.; Moher, D. The PRISMA statement for reporting systematic reviews and meta-analyses of studies that evaluate health care interventions: Explanation and elaboration. Ann. Intern. Med. 2009, 151, W-65-W-94. [CrossRef] [PubMed]

52. Crouch, M.; McKenzie, H. The logic of small samples in interview-based qualitative research. Soc. Sci. Inf. 2006, 45, 483-499. [CrossRef]

(C) 2020 by the authors. Licensee MDPI, Basel, Switzerland. This article is an open access article distributed under the terms and conditions of the Creative Commons Attribution (CC BY) license (http://creativecommons.org/licenses/by/4.0/). 